\title{
Cycle Testing of AgZ-PAN and HZ-PAN
}

Nuclear Technology

Research and Development

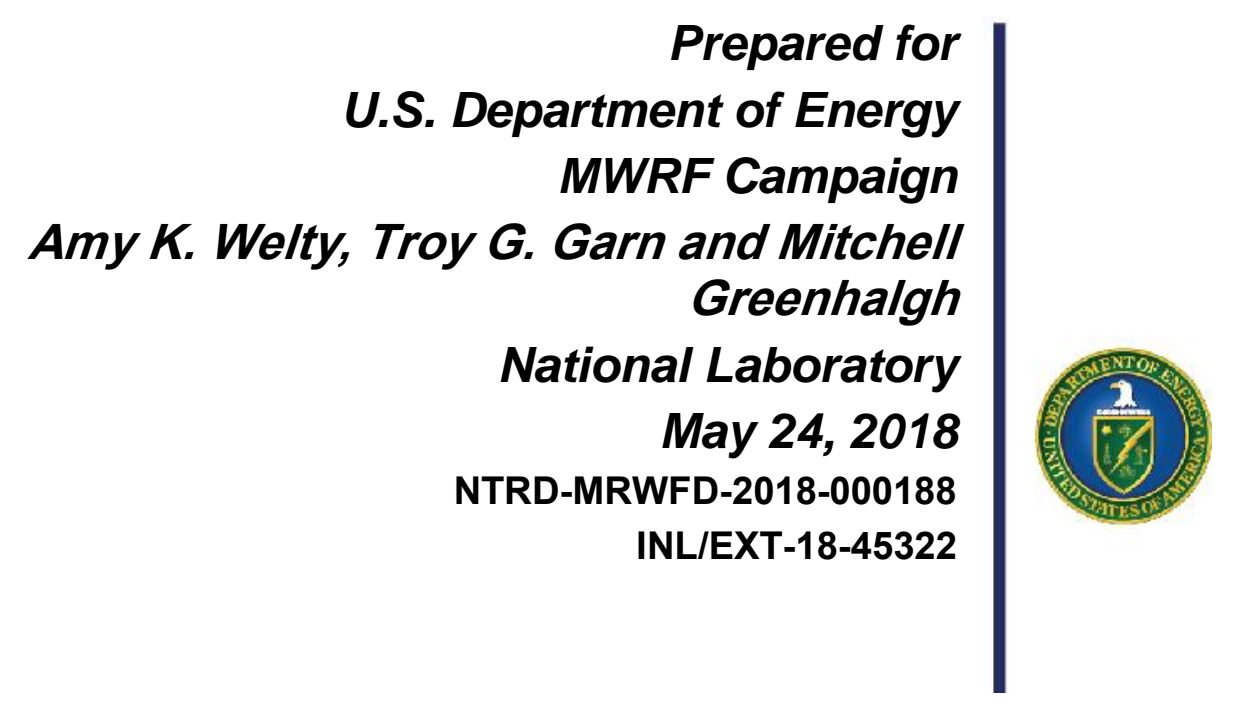





\section{DISCLAIMER}

This information was prepared as an account of work sponsored by an agency of the U.S. Government. Neither the U.S. Government nor any agency thereof, nor any of their employees, makes any warranty, expressed or implied, or assumes any legal liability or responsibility for the accuracy, completeness, or usefulness, of any information, apparatus, product, or process disclosed, or represents that its use would not infringe privately owned rights. References herein to any specific commercial product, process, or service by trade name, trade mark, manufacturer, or otherwise, does not necessarily constitute or imply its endorsement, recommendation, or favoring by the U.S. Government or any agency thereof. The views and opinions of authors expressed herein do not necessarily state or reflect those of the U.S. Government or any agency thereof. 




\section{SUMMARY}

Idaho National Laboratory (INL) has been producing and testing, as part of the Off-Gas Sigma Team, sorbents for the selective capture of xenon and krypton from surrogate nuclear fuel recycling off-gas streams. AgZ-PAN and HZ-PAN, both developed and produced at INL, have shown promising results for the selective capture and separation of xenon and krypton, respectively.

Previous testing of both sorbents has focused on saturation and initial breakthrough capacities across a variety of operating conditions. However, the sorbents can only be truly viable for use in a process if they demonstrate sufficient longevity through multiple adsorption/desorption cycles. This research, therefore, focused on putting both sorbents through multiple thermal swing adsorption/desorption cycles over the course of one year.

The primary focus of cycling tests was on AgZ-PAN, which previously demonstrated possible loss of capacity after multiple cycles. While capacity was shown to be recoverable over the short term, the goal was to ensure effective long-term viability so this series of test was designed to subject it to 100 thermal cycles, the estimated equivalent of one year of operation. HZ-PAN had not shown any deleterious effects from cycling during previous testing. Additionally, due to the colder temperatures required for $\mathrm{Kr}$ capture, each cycle required considerably more time to complete, so this sorbent was subjected to 50 cycles. Confirmation of sorbent capacities was achieved by performing intermittent capacity tests throughout the thermal cycling. Both sorbents maintained their capacities throughout the series, indicating promising potential for long-term reliability. 



\section{CONTENTS}

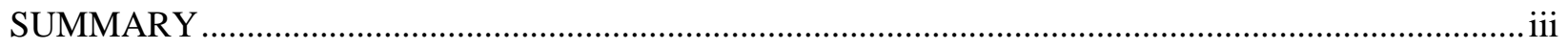

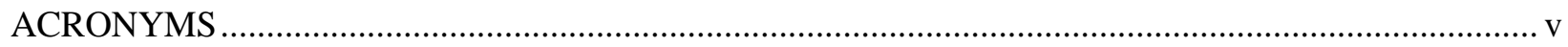

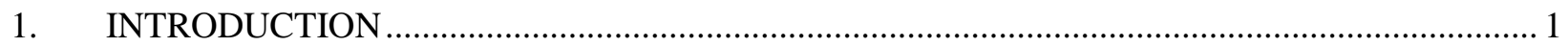

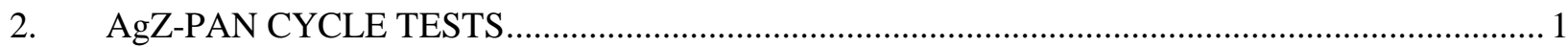

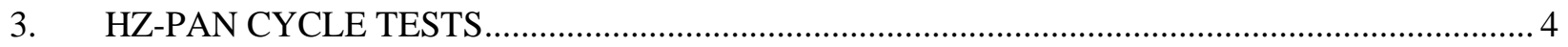

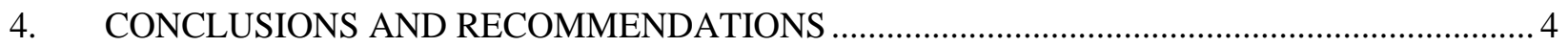

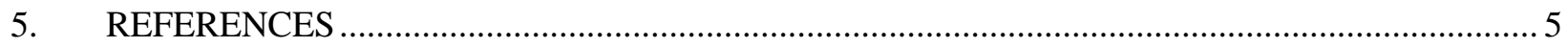

\section{FIGURES}

Figure 1 AgZ-PAN Xe Capacity at 295K using 1000 ppm Xe, 150 ppm Kr in Air feed gas......................2

Figure 2 AgZ-PAN Kr Capacity at 295K using 1000 ppm Xe, 150 ppm Kr in Air feed gas .....................2

Figure 3 HZ-PAN Kr capacity at $220 \mathrm{~K}$ using 2544 ppm $\mathrm{Kr}$ in $\mathrm{He}$ feed gas ............................................ 4

\section{TABLES}

Table 1 AgZ-PAN Cycle Testing Results. 3 


\section{ACRONYMS}

AgZ-PAN Silver-functionalized mordenite in polyacrylonitrile matrix

GC-TCD Gas Chromatograph with Thermal Conductivity Detector

HZ-PAN Hydrogen mordenite in polyacrylonitrile matrix

INL Idaho National Laboratory

K Kelvin

$\mathrm{Kr} \quad$ Krypton

PNNL Pacific Northwest National Laboratory

PPMV Part per million volume

SCCM Standard Cubic Centimeters per Minute

Xe Xenon 


\section{THERMAL CYCLING EVALUATIONS FOR AGZ-PAN AND HZ-PAN}

\section{INTRODUCTION}

The Off-Gas Sigma Team is focused on mitigation of environmental emissions from used nuclear fuel recycling. Ongoing research at the INL, which includes producing and testing sorbents for the selective capture of xenon and krypton from surrogate nuclear fuel recycling off-gas streams, has yielded good results with respect to capacities for xenon and krypton across a range of operating conditions.

In order to ensure that the sorbents are truly viable for long-term use in a process, they must maintain capacity after multiple thermal cycles of adsorption and desorption. Both sorbents were subjected to multiple thermal cycles to determine what, if any, effect continuous operation may have on their ability to capture xenon and krypton.

\section{AgZ-PAN CYCLE TESTS}

A sample of AgZ-PAN that had previously been used for adsorption testing was utilized for this series of tests. $6.84 \mathrm{~g}$ were placed in a $10.9 \mathrm{~mm}$ ID by $152 \mathrm{~mm}$ stainless steel column. The column was fitted with a Watlow silicone rubber insulating line heater to ensure even, controlled heat distribution. A DigiSense standard programmable temperature controller, coupled with a type $\mathrm{K}$ thermocouple was used to ensure accurate temperature control.

During thermal cycling, certified hydrocarbon-free air through the columns was controlled via a MKS thermal mass flow controller at $50 \mathrm{sccm}$. The temperature controller was programmed to ramp temperature from ambient up to $420 \mathrm{~K}$ over one hour, followed by ramping back down to $305 \mathrm{~K}$ over four hours. The controller was capable of up to eight cycles in succession, holding the final temperature at completion of each series.

AgZ-PAN capacities were tested using $1000 \mathrm{ppm} \mathrm{Xe}$ and $150 \mathrm{ppm} \mathrm{Kr}$ in a balance of air at $295 \mathrm{~K}$. Gas analysis for capacity testing was accomplished via an Agilent gas chromatograph with a thermal conductivity detector (GC-TCD) with automatic gas sampling. Each analytical cycle took 10-11 minutes to complete.

The AgZ-PAN used for this testing had previously been subjected to 17 thermal cycles from previous capacity and superficial velocity testing. For this series, it was subjected to an addition 100 thermal cycles, with capacity determinations after $24,35,53,70,88$, and 117 total cycles. As may be seen in Figures 1 and 2, sorbent performance remained essentially unchanged over the entire series of thermal cycles. 


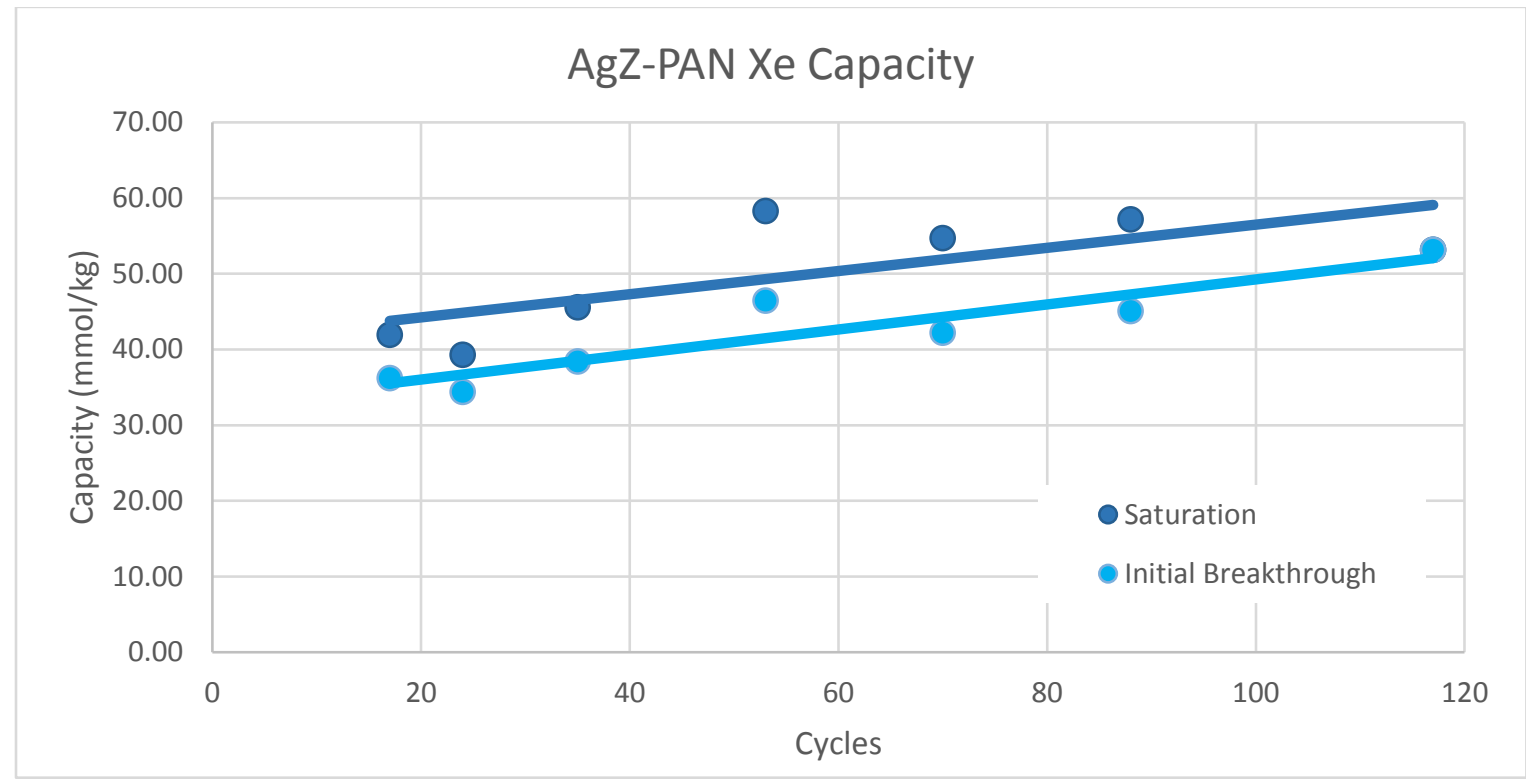

Figure 1 AgZ-PAN Xe Capacity at 295K using 1000 ppm Xe, 150 ppm Kr in Air feed gas

Initial performance of this sorbent prior to cycle testing was based on the average results from previous tests under the same or similar flow conditions (Welty, Greenhalgh, \& Garn, 2016), reported in Table 1 at 17 cycles which is the number of cycles the sorbent was subjected to prior to this series of thermal cycles.

Capacities xenon did not deteriorate throughout testing. While there was an increase in xenon capacity as cycles progressed, which also occurred during previous superficial velocity testing, the increasing trend is a fairly recent development that has not been confirmed sufficiently to claim improved performance with additional cycles. It is, however, an intriguing trend which warrants further investigation.

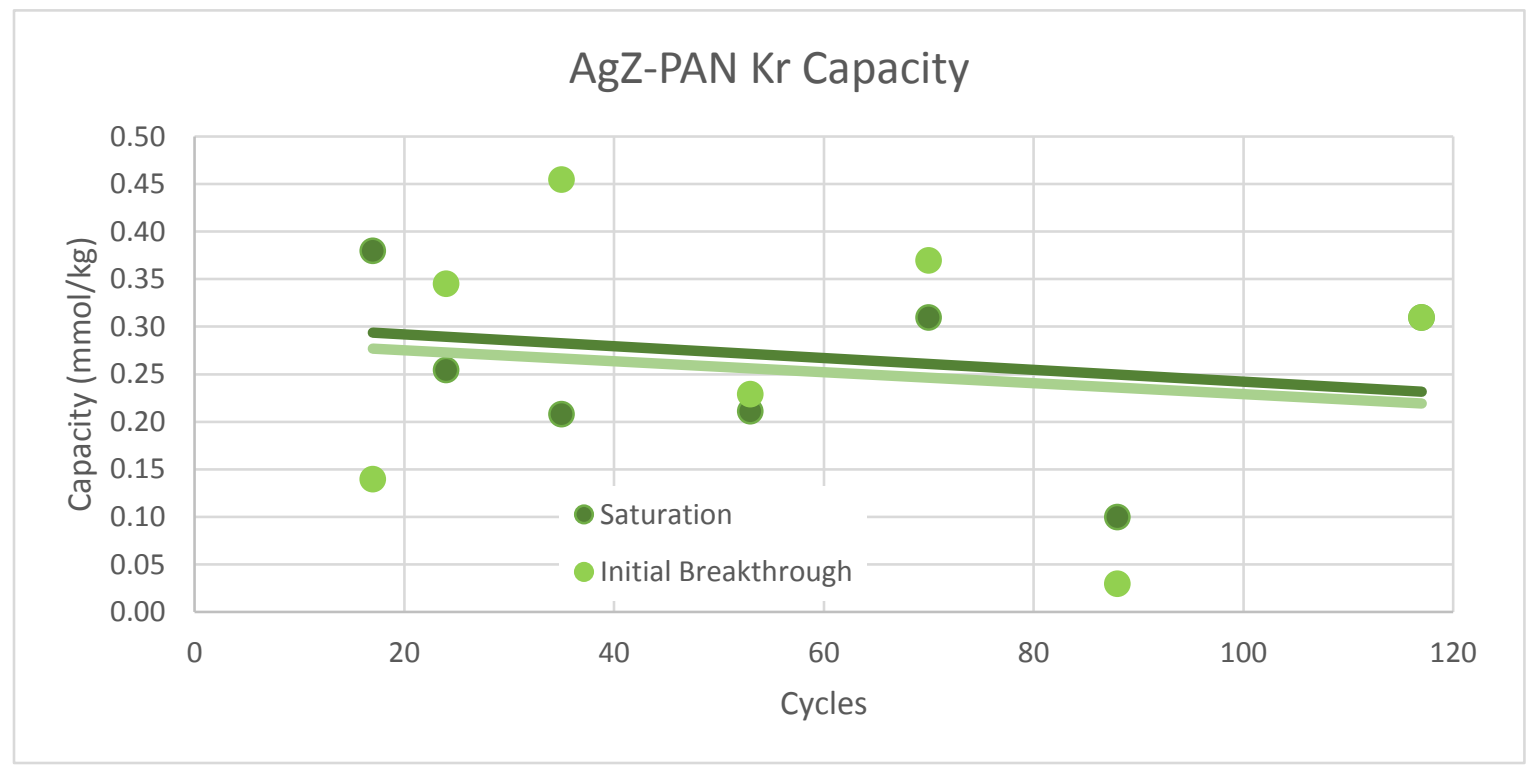

Figure 2 AgZ-PAN Kr Capacity at 295K using 1000 ppm Xe, 150 ppm Kr in Air feed gas 
Some scatter appears in the krypton data, but it is largely a matter of graph scale. The standard deviation for saturation capacity was only 0.08 . The initial breakthrough capacity standard deviation was higher, at 0.14 , due to the nearly immediate breakthrough of krypton. With a 10 minute analytical delay through the GC-TCD, a few seconds difference in the time it takes to route feed gas through the column alters calculated krypton, affecting breakthrough capacity more strongly than saturation capacity.

There is significantly more scatter in the nitrogen data, however, due to the overwhelming presence of nitrogen in air. Also of note, breakthrough capacities for nitrogen are higher than saturation capacities. This is attributable to nitrogen initially filling in the empty spaces in the packed column, creating the appearance of higher adsorption at the first analytical point.

Table 1 AgZ-PAN Cycle Testing Results

\begin{tabular}{r|ccc|ccc} 
& \multicolumn{2}{|c}{ Saturation Capacity } & \multicolumn{3}{c}{ Selectivity } \\
Cycles & $\mathbf{X e}$ & $\mathbf{K r}$ & $\mathbf{\mathbf { N } _ { \mathbf { 2 } }}$ & $\mathbf{X e} / \mathbf{K r}$ & $\mathbf{X e} / \mathbf{N}_{\mathbf{2}}$ & $\mathbf{K r} / \mathbf{N}_{\mathbf{2}}$ \\
\hline 17 & 41.94 & 0.38 & 168.00 & 16.56 & 197.22 & 11.91 \\
24 & 39.30 & 0.25 & 600.62 & 21.06 & 69.17 & 3.28 \\
35 & 45.55 & 0.21 & 1154.06 & 12.89 & 56.44 & 4.38 \\
53 & 58.26 & 0.21 & 545.28 & 39.74 & 186.73 & 4.70 \\
70 & 54.71 & 0.31 & 584.56 & 25.02 & 301.21 & 12.04 \\
88 & 57.19 & 0.1 & 103.79 & 97.42 & 335.00 & 3.44 \\
117 & 53.13 & 0.31 & 1026.19 & 40.78 & 77.6 & 1.9
\end{tabular}

\begin{tabular}{r|ccc|ccc} 
& \multicolumn{2}{|c}{ Breakthrough Capacity } & \multicolumn{3}{|c}{ Selectivity } \\
Cycles & $\mathbf{X e}$ & $\mathbf{K r}$ & $\mathbf{N} \mathbf{N}_{2}$ & $\mathbf{X} / \mathbf{K r}$ & $\mathbf{X e} / \mathbf{N}_{\mathbf{2}}$ & $\mathbf{K r} / \mathbf{N}_{\mathbf{2}}$ \\
\hline 17 & 36.20 & 0.14 & 731.51 & 16.56 & 197.22 & 11.91 \\
24 & 34.40 & 0.35 & 803.58 & 21.06 & 69.17 & 3.28 \\
35 & 38.38 & 0.45 & 2395.65 & 12.89 & 56.44 & 4.38 \\
53 & 46.42 & 0.23 & 1207.10 & 39.74 & 186.73 & 4.70 \\
70 & 42.22 & 0.37 & 924.12 & 25.02 & 301.21 & 12.04 \\
88 & 45.06 & 0.03 & 168.26 & 97.42 & 335.00 & 3.44 \\
117 & 53.13 & 0.31 & 1026.19 & 40.78 & 77.6 & 1.9
\end{tabular}




\section{HZ-PAN CYCLE TESTS}

A sample of HZ-PAN that had previously been used for adsorption testing was utilized for this series of tests. The same column and test set-up, previously described in Section 2, were used for HZ-PAN cycle testing. The column was filled with $3.80 \mathrm{~g}$ of HZ-PAN. Due to the cryogenic temperatures required to effectively adsorb krypton, the insulated column was placed in a Stirling Ultracold portable cooler.

The temperature controller was programmed to ramp temperature from $191 \mathrm{~K}$ up to $370 \mathrm{~K}$ over one hour, followed by cooling own to $191 \mathrm{~K}$. Due to the cold temperatures required, the HZ-PAN tests could not be programmed for a rapid series of eight thermal cycles as the Stirling cooler needed to be shut down during heating cycles. Consequently, one thermal cycle took two days instead of the five hours required for AgZPAN.

HZ-PAN capacities were tested using $2544 \mathrm{ppm} \mathrm{Kr}$ in a balance of helium at $220 \mathrm{~K}$. Gas analysis for capacity testing was accomplished via GC-TCD with automatic gas sampling. Each analytical cycle took 10-11 minutes to complete. Although capacity testing with feed gas with $\mathrm{Kr}$ in air at $191 \mathrm{~K}$ would have been more analogous to operating conditions, high $\mathrm{Kr}$ concentration feed gas in a balance of $\mathrm{He}$ at $220 \mathrm{~K}$ was chosen for two reasons: 1) most available data from previous testing of HZ-PAN with Kr used this same gas mix, and 2) the higher concentration of $\mathrm{Kr}$ decreased the time required to complete testing, allowing more cycles to be completed.

The HZ-PAN used for this testing had previously been subjected to 11 thermal cycles from superficial velocity testing. For this series, it was subjected to an addition 49 thermal cycles, with capacity determinations after 35 and 60 total cycles. As may be seen in Figures 3, sorbent performance remained essentially unchanged over the series of thermal cycles.

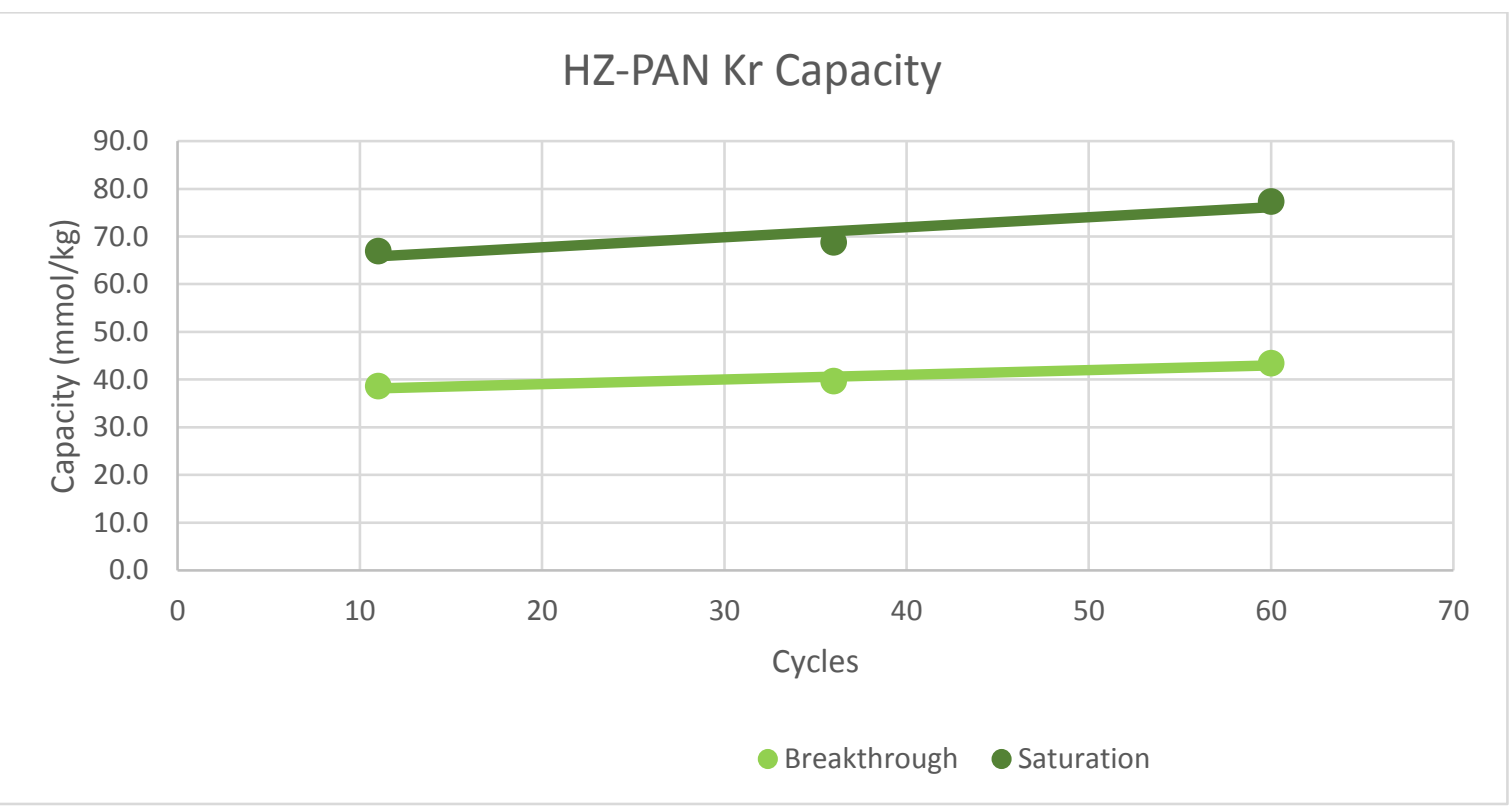

Figure 3 HZ-PAN Kr capacity at $220 \mathrm{~K}$ using $2544 \mathrm{ppm} \mathrm{Kr}$ in He feed gas

\section{CONCLUSIONS AND RECOMMENDATIONS}

AgZ-PAN and HZ-PAN have thus far demonstrated consistent ability to capture and separate xenon and krypton. This series of cycling tests represents approximately one year of operation for AgZ-PAN and one half year of operation for HZ-PAN with no deleterious effect on capacity. 
It is recommended that cycle testing continue as long as possible to determine the maximum number of cycles achievable for each sorbent before they break down, either physically or chemically, to the point where acceptable performance is no longer achievable.

\section{REFERENCES}

Welty, A. K., Greenhalgh, M., \& Garn, T. G. (2016). Superficial Velocity Effects on HZ-PAN and AgZPAN for Kr/Xe Capture. INL/EXT-16-38331. 